Western University

Scholarship@Western

Department of Economics Research Reports

Economics Working Papers Archive

1991

\title{
Optimal International Trade Agreements and Dispute Settlement Procedures
}

Rodney D. Ludema

Follow this and additional works at: https://ir.lib.uwo.ca/economicsresrpt

Part of the Economics Commons

Citation of this paper:

Ludema, Rodney D.. "Optimal International Trade Agreements and Dispute Settlement Procedures." Department of Economics Research Reports, 9101. London, ON: Department of Economics, University of Western Ontario (1991). 
RESE'ARCH REPORT 9101

OPTIMAL INTERNATIONAL TRADE AGREEMENTS

AND DISPUTE SETILEMENT PROCEDURES

by

Rodney D. Ludema

December 1990

\author{
Department of Economics \\ Social Science Centre \\ University of Western Ontario \\ London, Ontario, Canada \\ N6A $5 \mathrm{C} 2$
}

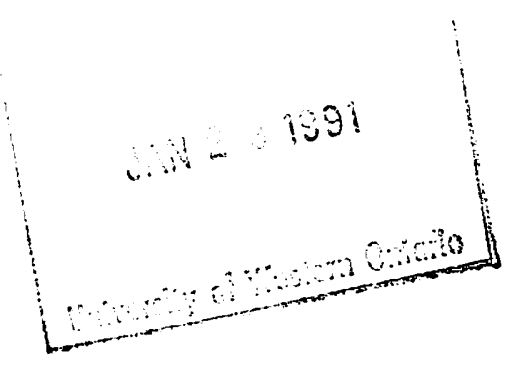




\section{OPTIMAL INTERNATIONAL TRADE AGREEMENTS AND DISPUTE SETTLEMENT PROCEDURES}

Rodney D. Ludema

University of Western Ontario

December 1990

JEL Classification: 420

Key words: Trade agreements, Dispute settlement, Renegotiation

Abstract: An infinitely-repeated tariff game is used to characterize optimal (welfare-maximizing and self-enforcing) international trade agreements under different assumptions about dispute settlement. Without dispute settlement, optimal agreements resort to autarky, if only temporarily, should a violation occur. Such agreements support free trade, for low discounting, and otherwise sustain lower tariffs than any other agreement. A dispute settlement procedure (DSP) restricts the set of possible agreements to those which are renegotiation-proof, as in Pearce (1987). A DSP-constrained optimal agreement never supports free trade and results in higher tariffs than the no DSP case. Finally, optimal tariff agreements are shown to give higher welfare than optimal quota agreements.

Thanks to Niels Anthonisen, Kyle Bagwell, Jagdish Bhagwati, Ig Horstmann and John Whalley for suggestions and help.

Rodney D. Ludema, Department of Economics, University of Western Ontario, London, Ontario N6A 5C2, (519) 661-3493 


\section{INTRODUCTION}

Many international trade policies have the feature that if they profit the country employing them, they harm the rest of the world to an even greater degree. When every country has access to a policy of this type, there is always a cooperative arrangement to restrict the policy's use, which if could be enforced would benefit every country. It follows that in these situations sovereign nations have an interest in cooperating with one another on trade policy to the greatest possible extent. An important limitation on this cooperation is that international trade agreements must be self-enforcing and hence must provide for sanctions against would-be violators, sanctions which themselves must be self-enforcing. To what extent sanctions can be meted out in the appropriate contingencies depends upon the extent of communication possible and rules under which countries negotiate agreements and settle disputes. This paper explores the limits of self-enforcing international trade agreements and the effects of these rules, with a view toward identifying agreements yielding the highest levels of welfare to all signatories.

Recent literature has addressed the problem of trade policy cooperation by modeling the relationship between countries as a repeated game, demonstrating how a system of (perfect) equilibrium sanctions can be used to support cooperation [e.g., Jensen and Thursby (1980), Dixit (1987), Copeland (1988), Bagwell and Staiger (1990), Ludema (1990), Riezman (1990)]. Reversion to an interior Nash equilibrium of the associated stage game is the most popular form of sanction, though it generally does not result in the best agreement, in sense of supporting the lowest tariff levels for an arbitrary discount factor. In this respect, the bulk of the literature is lacking on both normative and positive grounds, unless a useful theory can be found to explain why countries would select inferior agreements. Following Abreu's (1983) work, Dixit (1987) and Ludema (1990) addressed the problem of finding optimal agreements, observing that the strongest credible sanctions are those that use highest tariffs available. A remaining question, however, is this: if countries were ever to reach a state in which sanctions were required, why would they not simply renegotiate the original agreement? But if they renegotiate the agreement, what becomes of the sanctions and, indeed, the agreement itself? 1

\footnotetext{
${ }^{1}$ Recently, Cotter and Mitchell (1990) address this issue, though their approach is substantially different from the one taken here.
} 
Avoiding sanctions through renegotiation in international trade agreements is not unusual. Virtually all international trade agreements provide their members with fora, in which to communicate their complaints, investigate perceived deviations and discuss the use of sanctions. The General Agreement on Tariffs and Trade (GATT) contains dispute settlement procedures for virtually every section of the agreement, and in areas where unilateral action is permitted, negotiation is encouraged.

Even the famous "Chicken War" of the 1960s was more negotiation than war. When the EC applied a tariff on poultry higher than its "GATT bound concession," the relevant GATT article required that it negotiate with the US over "compensation." When there was no agreement, the GATT Director-General appointed a panel to recommended sanctions acceptable to both sides of the dispute. 2 Thus according to Conybeare (1987), "the possible cooperationinducing effects of many rounds of retaliation and counter retaliation by parties using contingent strategies of retaliation were thereby relinquished."

Observers of the GATT regularly argue that current dispute settlement procedures are too easily influenced by political considerations--too equivocal about what constitutes a breach of the agreement and too reluctant to reach decisions on sanctions, for fear of objection from either side of a dispute. ${ }^{3}$ Whether and to what extent the renegotiation implicit in dispute settlement procedures undermines the credibility of trade agreements is an important issue both in view of the recent literature and on-going calls for dispute settlement reform.

This paper investigates the form of optimal international trade agreements, both in the absence and presence of a dispute settlement procedure (DSP), using an infinitely-repeated version of standard two-by-two noncooperative tariff game due to Scitovszky (1942) and Johnson (1953/54). At the outset of the game, the countries write down an agreement, defined as a pair of historydependent strategies that are suggested (but not required) to be implemented. Countries have the right to make whatever decisions are in their interests upon the on-set of the game, so that only agreements which are noncooperative equilibria will be implemented. In a typical equilibrium, countries will prevent each other from pursuing protectionist policies by threatening each other with

2 See Jackson and Davey (1986) and Conybeare (1987).

${ }^{3}$ For example, the US House Ways and Means Committee Report on the 1974 Trade Act, cited in Jackson and Davey (1986, p 352). 
retaliatory sanctions that would result in a punishment equilibrium harmful to both sides. An optimal trade policy agreement will achieve the lowest levels of protection and the most severe credible threat. The key distinction between agreements with and without DSP is the degree of communication available after the on-set of the game.

When no intra-game communication is possible, each country's expectation about what other country will do in any contingency depends solely upon the agreement reached prior to the game. This can be thought of as the case of a degenerate DSP or no DSP. In this case, there is no limit on the severity of the sanctions that can be threatened, except that each country have an incentive to carry out its part, given the strategy of the other. Under quite general circumstances, the most severe credible punishment equilibrium will be autarky for a long (but not always infinite) time. The optimal tariff agreement is a bargaining solution on the set of outcomes that can be "supported" by (i.e., sustained for fear of) this punishment. The optimal tariff agreement will be a stationary equilibrium and give equal welfare to both countries, when the countries themselves are symmetric. When discounting is not too great, free trade will be obtainable in this environment, and when free trade cannot be obtained, no other credible agreement gives lower tariffs.

When communication is possible after an agreement has begun (which is a fair representation of most modern trade agreements), these results may differ substantially; however, the rules under which countries communicate and take joint action are of utmost importance. It is not enough to suggest that countries renegotiate in exactly the same way as they negotiate prior to the game, because prior to the game there is no history, and without history-dependent actions, no cooperation is possible. The approach taken here is to attempt to approximate some of the rules found in actual international trade agreements by writingdown what might be called a dispute settlement procedure -- a rule specifying outcomes to follow violations of the agreement in accordance with GATT conventions of reciprocity and consensus. It will be shown that by imposing a consistency requirement on the DSP, optimal tariff agreements that support cooperation exist, have a structure similar to the optimal agreements without the DSP, and are "renegotiation-proof" in the sense of Pearce (1987). However, the presence of a DSP unambiguously reduces the welfare each country receives in the optimal tariff agreement, relative to the no DSP case, and it makes the achievement of free trade impossible, for any amount of discounting.

Central to these results is the difference in the role of discounting in each 
case. For a given threat of sanctions, the more countries care about the future (or lower response time), the less significant is the temptation to deviate from an agreement relative to the cost associated with its punishment equilibrium. Further, without a DSP, lower discounting enables longer periods of sanctions to be sustained in the punishment equilibrium, because a deviation from that equilibrium would simply result in its re-imposition. Both of these effects work to improve the cooperation supportable in an agreement. In the presence of a DSP, however, a country will reject any punishment equilibrium recommended by the DSP that does not maximize its present discounted welfare level (subject to reciprocity or equal treatment). Thus, although less discounting reduces the relative temptation to deviate from an agreement, it also induces countries to demand less severe punishments (i.e. a shorter period of sanctions) as costs associated with long, drawn-out sanctions grow. As these effects work in opposite directions, improvements in cooperation due to lower discounting are mitigated.

Although most of the results obtained here are for the case of ad valorem tariffs, other instruments are analyzed in the same fashion. By way of comparison, it turns out that optimal tariff agreements are generally (weakly) better from a welfare standpoint than optimal quota agreements, because quotas agreements carry higher gains to deviating. This is always true in the presence of a DSP, and it is true in the absence of a DSP, provided the maximum tariff is unrestricted. This result supports the argument for converting non-tariff barriers into tariff equivalents before agreeing to bindings.

The paper is divided into several sections. Section 2 sets out the model in two parts: the basic static model that has traditionally been used to study the issue of tariffs and retaliation and a repeated game version of it. Section 3 examines optimal tariff agreements in the absence of a DSP. This provides a formal generalization of the work of Dixit (1987) and Ludema (1990), as well as a benchmark for section 4 . Section 4 introduces the DSP and finds optimal tariff agreements in this context. In section 5, the results obtained for tariffs are contrasted with the analogous results for the case of quotas. Section 6 provides a simple example to illustrate optimal tariff agreements with and without a DSP. The conclusion is found in section 7 .

\section{1 THE STAGE GAME}

Let the world be divided into two countries, 1 and 2, with price-taking 
agents and two goods, $A$ and $B$. In each country there is a government assumed to levy an ad valorem tariff on imports in an effort to maximize welfare, subject to a convex production-possibility set. Both countries are assumed large enough so that tariffs influence the terms of trade. Suppose welfare can be represented by a continuously differentiable, quasi-concave social welfare function defined over consumption of $A$ and $B$. To insure that the offer curves have the conventional shape, we allow no domestic distortions or inferiority in consumption and assume a unique trading equilibrium for any combination of tariffs.

Take good $B$ to be the numeraire, and let $p_{i}$ denote the domestic price of good $A$ in country $i, x_{i} \in X_{i}$, its tariff, and $\pi$ the terms of trade. In the absence of other transport costs, these variables are related by:

$$
\mathrm{p}_{1}=\pi\left(1+\mathrm{x}_{1}\right) \quad \mathrm{p}_{2}=\frac{\pi}{\left(1+\mathrm{x}_{2}\right)}
$$

Let the autarky prices of good $A$, denoted $P_{i}$, be such that $P_{1}>P_{2}$. When $p_{1} \leq P_{1}$ and $p_{2} \geq P_{2}$, country 1 imports good $A$ and exports good $B$ to country 2 . The (just) prohibitive tariffs are defined by:

$$
\mathrm{z}_{\mathrm{i}}\left(\mathrm{x}_{\mathrm{j}}\right)=\left(\frac{\mathrm{P}_{1}}{\mathrm{P}_{2}}\right)\left(\frac{1}{1+\mathrm{x}_{\mathrm{j}}}\right)-1 \quad \mathrm{i}, \mathrm{j}=1,2, \mathrm{i} \neq \mathrm{j}
$$

Since $z_{i}\left(x_{j}\right)$ (possibly infinite) equates $\left(P_{1} / P_{2}\right)$ with $\left(p_{1} / p_{2}\right)$, it is the smallest tariff large enough to bring about autarky (or more accurately, zero gains from trade) in the presence of a foreign tariff $x_{j}$. Let $\underline{x}=\left(P_{1} / P_{2}\right)^{1 / 2}-1$ be the minimum tariff such that, if it were used by both countries, autarky would prevail, and let $z \equiv z_{i}(0)$ (for notational convenience). The strategy sets are defined as $\mathbf{X}_{\mathbf{i}} \equiv[0, \bar{x}]$, where $\bar{x} \leq z$. There is no reason to consider tariffs larger than $z$, since they only continue autarky. Ruling out import subsidies, however, is not a trivial assumption, but it enables a much cleaner representation of the payoffs and corresponding results.

The welfare functions can be written in implicit form as continuous functions of the tariff levels: $W_{i}=W_{i}\left(x_{1}, x_{2}\right)$, with welfare in autarky normalized to zero, i.e. $W_{i}\left(z_{1}\left(x_{2}\right), x_{2}\right)=W_{i}\left(x_{1}, z_{2}\left(x_{1}\right)\right) \equiv 0$ for $i=1,2.4$ Welfare will reach a

\footnotetext{
${ }^{4}$ Since a country can never inflict anything worse than autarky on its neighbor, the
} 
maximum at the optimal tariff, which for country $i$ is implicitly defined by:

$$
y_{i}\left(x_{j}\right)=\frac{1}{\varepsilon_{j}-1} \quad i, j=1,2, i \neq j
$$

Here $\varepsilon_{j}$ denotes the elasticity of $j$ 's import demand with respect to a change in the terms of trade, which is greater than 1 in the neighborhood of the optimal tariff. Define $\omega_{1}\left(x_{2}\right) \equiv W_{1}\left(y_{1}\left(x_{2}\right), x_{2}\right)$ and $\omega_{2}\left(x_{1}\right) \equiv W_{2}\left(x_{1}, y_{2}\left(x_{1}\right)\right)$ as the welfare each country associates with the optimal tariff.

From the assumptions made so far, three well-known results follow: For any nonprohibitive $x_{j}$, (1) $W_{i}$ is quasi-concave in $x_{i}$, increasing in $x_{i}$ up to $y_{i}\left(x_{j}\right)$, decreasing thereafter to $z_{i}\left(x_{j}\right)$, and further increases in $x_{i}$ merely continue autarky and hence are partially ordered [Bhagwati and Kemp (1969)]; (2) $\mathrm{W}_{\mathrm{i}}$ is nonincreasing in $x_{j}$ [e.g. see Jones (1969)], and by the envelope theorem, $\omega_{i}\left(x_{i}\right)$ is also nonincreasing; and (3) the function $y_{i}\left(x_{j}\right)$ is single-valued, continuous, strictly positive and nonprohibitive. It will also be convenient to assume that world welfare $\left(W_{1}+W_{2}\right)$ is quasi-concave and $\omega_{i}\left(x_{j}\right)$ is convex. 5

Result (3) above implies the existence of at least one an interior Nash equilibrium $\left(x_{1}{ }^{n}, x_{2}{ }^{n}\right)$, where $x_{i}{ }^{n}=y_{i}\left(x_{j}^{n}\right)$ for $i, j=1,2, i \neq j$. There will also typically be a corner solution. In autarky, the elasticity of import demand is infinite, so $\mathrm{y}_{\mathrm{i}}(\mathrm{z})=0$; however, the optimal tariff in this case is not unique. Indeed, any positive tariff, including $x_{i}=z$, is a best response to $x_{j}=z$. This implies that autarky is a Nash equilibrium outcome when $\bar{x}=z$, though the equilibrium strategies that bring about autarky are dominated.6

minimax payoff for both countries is not less than zero.

${ }^{5}$ This will always hold when the proportional change in $\varepsilon_{j}$ in response to a small change in $x_{i}$ is not too large. It is trivially satisfied by the well-known constant offer curve elasticity example used by Johnson (53/54) and found at the end of this paper. ${ }^{6}$ The strategy $z$ is dominated for $i$ because no other $x_{i}$ is worse than $z$ for any $x_{j}$, and some $x_{i}$ are better for some $x_{j}$. 
FIGURE 1

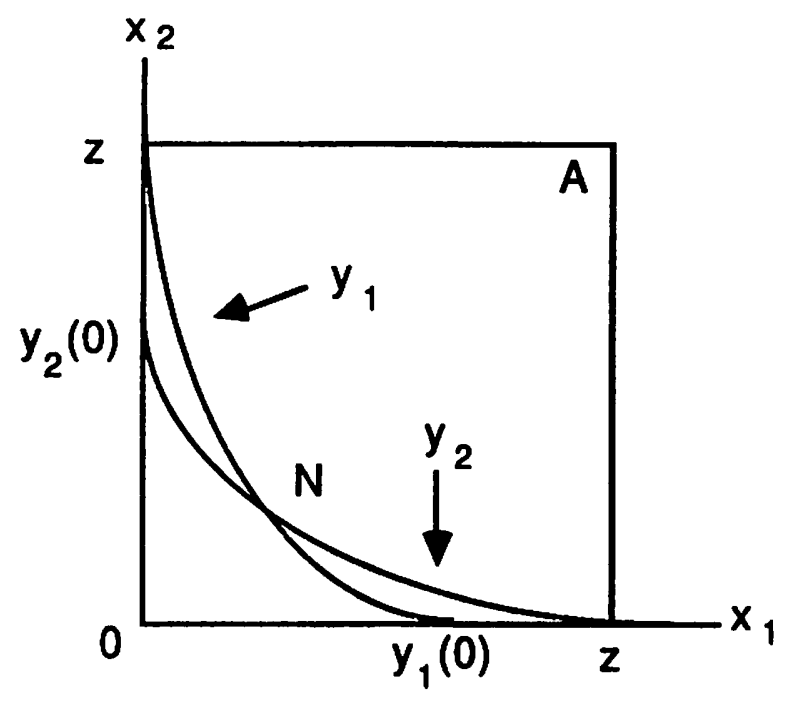

Figure 1 illustrates the best reply mappings and the Nash equilibria of the stage game, for the special case in which the optimal tariff functions are monotonic. The autarky equilibrium $(z, z)$ is denoted $A$, and the interior Nash equilibrium is at $N$. In general, multiple interior equilibria are possible, as demonstrated by Johnson (53/54).

That autarky may be a Nash equilibrium in the stage game is both problematic and useful. It is problematic, because it is an unstable equilibrium: the state of almost autarky is not almost a Nash equilibrium, because the best response to an almost prohibitive tariff is an almost zero one. Were it impossible for a country to unilaterally and completely eliminate trade with its tariff (it might be that smuggling can not be unilaterally prevented), then the autarky equilibrium will cease to exist. Because of its instability, most authors assume away the autarkic equilibrium. However, this equilibrium is useful from a theoretical standpoint, because it implies eternal autarky can be used as a credible punishment for deviation from an agreement in the context of a repeated game. The present model is parameterized according to $\bar{x}$, the maximum tariff: if $\bar{x}=z$, then autarky is a Nash equilibrium in the stage game, otherwise, it is not. In any event, it turns out autarky will play a role in the optimal tariff agreement, provided autarky is feasible (i.e. $\underline{x} \leq \bar{x}$ ); hence, the results are not very sensitive to restrictions on the maximum tariff.?

${ }^{7}$ Dixit (1987) considers the alternative interpretation of a tariff as a wedge 


\subsection{THE REPEATED GAME}

Now consider the infinitely repeated version of the game just described. Let $s(t)$ denote a pair of tariffs $\left(x_{1}(t), x_{2}(t)\right)$ in period $t$, for $t=0,1,2, \ldots$. Over time there will develop an infinite sequence of such pairs, $s=\{s(t)\}_{t=0}^{\infty}$, called an outcome path. The welfare associated with an outcome path $s$ will be the sum of the welfare attained at each stage discounted by the factor $\delta \in(0,1)$ and normalized by $(1-\delta)$ :

$$
w_{i}(s)=(1-\delta) \sum_{t=0}^{\infty} \delta t W_{i}(s(t))
$$

This normalization facilitates comparison between the repeated game and stage game payoffs.

In each period $t=1,2 \ldots$, there is a history $h(t)$, which is list of all the tariffs played by both countries up through the period $t-1$. Thus we define $h(t)=(s(t-$ $1), h(t-1))$ and $h(1)=s(0)$. A pure strategy for government $i$ will be denoted $\sigma_{i}=$ $\left\{\sigma_{i}(t)\right\}_{t=0}^{\infty}$, an infinite sequence of functions, where each $\sigma_{i}(t)$ selects a tariff $x_{i}(t) \epsilon$ $X$ as a function of the history $h(t)$ and $\sigma_{i}(0)=x_{i}(0)$. We will call a pair of strategies $\phi=\left(\sigma_{1}, \sigma_{2}\right)$ an agreement (how agreements are reached will be explained later). If followed indefinitely, the agreement $\phi$ will completely determine an outcome path $s_{\phi}$ and with it a payoff for each country $w_{i}\left(s_{\phi}\right)$.

Governments are free to deviate from an agreement at any time. A oneshot deviation by country $i$ from an agreement $\phi$ in period $t$ can be defined as $x_{i}(t) \neq \sigma_{i}(t)$, followed by $x_{i}(t+1)=\sigma_{i}(t+1)$. In other words, country $i$ deviates by choosing a tariff different from the one agreed upon and then returns to the agreement thereafter. It can be shown that one-shot deviations are the only type of deviations that need to be considered. 8 When a country deviates from $\phi$, the initial outcome path $s_{\phi}$ is disrupted, and when the country resumes compliance with $\phi$, a new path, call it $s_{\phi}^{\prime}$ is begun. This path is followed until another deviation occurs causing a move to another path, and so on. Hence, an

maintaining the home price above the foreign price, thus acting as a tax if the good is imported and a subsidy if the good exported. This also rules out autarky as a Nash equilibrium, and all the results of this paper apply to this case also.

8 In equilibrium, if a one-shot deviation is not optimal, then a multi-period deviation is not optimal either. See Abreu (1983) for proof. 
agreement can be treated as a rule specifying an initial outcome path and outcome paths to be followed after any deviation. In what follows, we will refer to a deviation from an agreement while following a path $s$ as a deviation from $s$ itself.

Now consider three outcome paths, an initial path $\mathrm{s}^{0}$, and two punishment paths $s^{1}$ and $s^{2}$, and the following rule (R):

1) Choose $s^{0}$ for all $t$, until a country deviates.

2) If country $i$ deviates from any ongoing path, start (or restart) the path $s^{i}$

3) Ignore simultaneous deviations.

The paths $s^{0}, s^{1}$, and $s^{2}$ along with $R$ constitute an agreement. 9 The initial path $s^{0}$ is followed if no deviation occurs, and the two punishment paths $s^{1}$ and $s^{2}$, are used whenever a deviation by one country does occur. If country $i$ deviates at any time, regardless what path is in progress, the path $s^{i}$ is begun. Such an agreement is a Nash equilibrium if no one has an incentive to deviate from the initial path. It is a subgame perfect equilibrium (SPE), if no country has an incentive to deviate from any path specified by the agreement, whether initial or punishment. Thus in an SPE, the initial path will always prevail, "supported" by the credible (i.e. SPE) threat of moving to a punishment path. The initial path will contain the behavior that we wish to support (low or no tariffs), while the punishment paths should support that behavior, through fear of the low payoffs associated with punishment (high tariffs).

The function $\omega_{i}(s(t))$ is the single-period welfare of country $i$ from selecting its optimal tariff in period $t$ in response to $x_{j}(t) \in s(t)$. Define $w_{i}(s ; t) \equiv(1-$ $\delta) \Sigma_{\tau}^{\infty}=0 \delta \tau(s(t+\tau))$ as the average welfare from following path $s$ indefinitely, evaluated beginning at time $t$. Then a necessary and sufficient condition for an agreement of the form above to be an SPE is:

$$
w_{i}\left(s^{j} ; t\right) \geq(1-\delta) \omega_{i}\left(s^{j}(t)\right)+\delta w\left(s^{i}\right)
$$

for all $\mathbf{i}=1,2$, all $\mathbf{j}=0,1,2$ and all $t$. The left side of (5) represents the country i's payoff (evaluated at $t$ ) to remaining on the ongoing path sj forever. The right

\footnotetext{
${ }^{9}$ Abreu (1988) shows that every purc strategy SPE path is the outcome of an agreement of this form.
} 
side is the sum of the immediate payoff in period to deviating from the ongoing path and the (discounted) punishment payoff. The punishment payoff term on the right side is discounted, because the change of paths from the ongoing path to $s^{i}$ does not take place until the period following a deviation.

Existence of an SPE is ensured by the existence of a Nash equilibrium in the stage game: an agreement to simply repeat the static Nash equilibrium each period regardless of history satisfies (5). Uniqueness is rare. In fact, the Folk Theorem [Fudenberg and Maskin (1986)] says that for a sufficiently high discount factor, any combination of individually rational average payoffs can be supported as an SPE.

\section{OPTIMAL TARIFF AGREEMENTS WITHOUT DISPUTE SETTLEMENT}

In addition to being interesting in their own right, optimal tariff agreements without dispute settlement provide a useful benchmark against which to evaluate the effects of dispute settlement procedures. Suppose countries can meet and reach agreements prior to the game, but for lack of dispute settlement procedures are enable communicate after the game has begun. An agreement satisfying subgame perfection will be self-enforcing, because no country will have an incentive to unilaterally deviate, and there is no means for coordinating joint deviations. Therefore, given the non-uniqueness of SPE agreements, the selection of "optimal" tariff agreements prior to the game must be made on criteria other than self-enforcement.

The approach taken here is to suppose countries select a bargaining solution on the set of Pareto optimal SPE agreements. The simplest (though not necessarily most realistic) way to do this is to assume the countries possess a certain degree of symmetry, so that bargaining theory would direct us to equal division of world welfare along the initial path. Therefore, we assume the functions $W_{i}(\cdot)$ for $i=1,2$ are symmetric, i.e., $W_{1}\left(x^{\prime}, x^{\prime \prime}\right)=W_{2}\left(x^{\prime \prime}, x^{\prime}\right)$ for all $x^{\prime}, x^{\prime \prime}$ (subsequently, the subscript $i$ will be dropped whenever a variable is equal for both countries and $W_{i}(x, x)$ will be written as simply $W(x)$ ). This implies $W(x)$ is strictly decreasing in $x$, except at $x=0$, where equal changes in $x_{1}$ and $x_{2}$ have off-setting terms of trade effects, and this allows us to treat free trade as the ultimate goal of cooperation. Of course, for $\delta$ high enough, the immediate gain from deviating from free trade is swamped even by the slightest punishment. Under such circumstances, no agreement can do better than one specifying free trade along the initial path and mild punishment paths; however, this is only 
true for high discount factors. A better definition of an optimal agreement is as one which maximizes initial path payoffs for an arbitrary discount factor. In sum, an optimal tariff agreement maximizes $w_{i}\left(s^{0}\right)$ subject to $w_{i}\left(s^{0}\right)=w_{j}\left(s^{0}\right)$ and (5) for any $\delta$.

Let $v_{i}(\delta)$ be the lowest average payoff country $i$ can receive in any SPE for discount factor $\delta$. By the symmetry of the welfare functions $v_{1}(\delta)=v_{2}(\delta)=v(\delta)$. Clearly, any punishment path resulting in $v(\delta)$ for either country is the most severe credible punishment path available for that country. Now let $x^{*}(\delta)$ maximize $W(x)$, subject to $W(x) \geq(1-\delta) \omega(x)-\delta v(\delta)$, and let $W^{*}(\delta)$ be the oneperiod payoff associated with $x^{*}(\delta)$. An agreement specifying $x^{*}(\delta)$ for both countries everywhere along the initial path, and specifying equilibrium punishment paths resulting in $v(\delta)$ for each country seems a very likely candidate for an agreement which is optimal for any discount factor. Proposition 1 confirms this intuition.

Proposition 1: An agreement specifying $\mathrm{s}^{0}=\left\{\mathrm{x}^{*}(\delta), \mathrm{x}^{*}(\delta)\right\}_{\mathrm{t}=0}^{\infty}$ and SPE paths $\mathrm{s}^{\mathrm{i}}$ such that $w_{i}\left(s^{i}\right)=v(\delta)$, for $i=1,2$ is an optimal tariff agreement for any discount factor.

Proof in Appendix.

The importance of proposition 1 is that the initial path is now known to be stationary and require equal tariffs by both countries. The problem of characterizing optimal tariff agreements is now reduced to finding the punishment paths that give rise to the lowest possible SPE payoffs. When autarky is a stage-game Nash equilibrium $(\bar{x}=z)$, this problem is easily solved. Autarky forever is both subgame perfect and the most severe possible punishment, since zero is the minimax payoff. Thus an optimal agreement for any value of the discount factor is one which asks both countries to impose the lowest tariff that can be supported by autarky forever, which is $x^{*}(\delta)$ for $v(\delta)=$ 0 . Free trade will be attainable with such an agreement for $\delta$ satisfying:

$$
\delta \geq \frac{\omega(0)-W(0)}{\omega(0)}
$$

The value (6) is the lowest possible $\delta$ for which free trade can be supported by 
any agreement, and for any $\delta$ less than (6), no agreement results in higher payoffs along the initial path than the optimal trade agreement.

When we do not allow autarky as a stage-game Nash equilibrium $(\bar{x}<z)$, autarky may still play a role in the optimal tariff agreement. However, instead of autarky forever, the punishment path of the optimal tariff agreement will specify autarky for a finite number of periods followed by a return to the $x^{*}(\delta)$ forever. Consider the following punishment path:

$$
q=\left\{(\bar{x}, \bar{x})_{t=0}^{T-1}, q(T),\left(x^{*}(\delta), x^{*}(\delta)\right)_{t=T+1}^{\infty}\right\}
$$

for $T \geq 1$. Along this path, both countries choose autarky $(\bar{x}, \bar{x})$ for $T$ periods, followed by a tariff pair $q(T)$, and then choose the lowest available tariffs $\left(x^{*}(\delta)\right.$, $\left.x^{*}(\delta)\right)$ thereafter. Since time is discrete, countries are restricted to choosing integers for the length of their autarky regime, rather than any real number. This is the sole purpose of $q(T)$, which is a randomized tariff pair taking on value $\bar{x}$ with probability $\lambda$ and $x^{*}(\delta)$ otherwise. ${ }^{10}$

In order for a punishment path of the type (7) so be part of an optimal tariff agreement, it must be possible to support autarky for at least one period. This is possible for high enough $\delta$ or $\bar{x}$, since the normalized one period payoff from deviating, $(1-\delta) \omega(\bar{x})$, is decreasing in $\delta$ and $\bar{x}$. Define $\bar{\delta} \equiv \omega(\bar{x}) / W^{*}(\bar{\delta})$. The next proposition establishes that a punishment path of form (7) will support the optimal tariff agreement for $\delta \geq \delta$.

Proposition 2: There exists a subgame perfect equilibrium punishment path $q^{*}$ of the form (7) such that $\operatorname{Ew}\left(q^{*}\right)=v(\delta)$, for $\delta \geq \delta$.

Proof in Appendix.

Propositions 1 and 2 together establish that the optimal tariff agreement, for $\delta \geq \delta$, has an initial path $s^{0}$ consisting of $x^{*}(\delta)$ for $v(\delta)=E w\left(q^{*}\right)$, which is

\footnotetext{
${ }^{10}$ It is assumed there exists a publicaly observable random variable with a continuous distribution. Then by choosing actions in $T$ according to the realization of the random variable, countries can choose autarky with any probability $\lambda \in[0,1]$ and $x *(\delta)$ with probability $(1-\lambda)$. Strictly speaking the equilibria found here are correlated, as in Aumann (1974). This one way to convexify the problem when the integer constraint is binding.
} 
supported by the credible threat to move to an equilibrium path $q^{*}$ of the form (7). To solve for $x^{*}(\delta), T^{*}$, and $\lambda^{*}$, one maximizes $W(x)$, subject to the following conditions:

$$
\begin{aligned}
& W(x) \geq(1-\delta) \omega(x)+\delta \rho W(x) \\
& \rho W(x) \geq(1-\delta) \omega(\bar{x})+\delta \rho W(x)
\end{aligned}
$$

where $\rho=\left\{\lambda \delta^{T+1}+(1-\lambda) \delta^{T}\right\}$. Conditions (8a) and (8b) are just rewritten from (5), using (7). Note that since (8b) holds with equality when $\operatorname{Ew}(q)=v(\delta)$, optimality of $\rho$ implies $\rho^{*}=\omega(\bar{x}) / W(x)$. This enables the collapse of $(8 a)$ and $(8 b)$ into a single condition:

$$
W(x) \geq(1-\delta) \omega(x)+\delta \omega(\bar{x})
$$

The payoff on the initial path must be at least as large as a discount-weighted average of the payoffs to deviating from each of the two paths. If $x^{*}(\delta)>0$, then condition (9) must hold with equality. If $x^{*}(\delta)=0$, condition (9) may not hold with equality, and if it does not, there exists a set of agreements with punishment paths of the form (7) that support free trade. Notice also that as $\bar{x}$ approaches $z, \delta$ goes to $0, \rho^{*}$ goes to zero (i.e. $T^{*}$ approaches infinity), $\operatorname{Ew}\left(q^{*}\right)$ goes to zero and $(9)$ reduces to $W(x) \geq(1-\delta) \omega(x)$.

Were autarky not feasible for any combination of tariffs ( i.e. if $\bar{x}<\underline{x}$ ) or discounting so severe that one period of autarky could not be supported in equilibrium (i.e. if $\delta<\delta$ ), then the analysis of optimal tariff agreements becomes more difficult. In general, the punishment paths would be asymmetric (i.e. countries would receive different payoffs along the paths) and nonstationary. Order can be restored only with further assumptions, such as that countries restrict their attention to symmetric paths, i.e. those giving equal payoffs on a period-by-period basis for both initial and punishment paths. Ludema (1990) shows that punishment paths on optimal tariff agreements have form similar to (7), when paths are assumed symmetric. The paths studied so far (where $\bar{x} \geq \underline{x}$ and $\delta \geq \delta$ ) have this property, but not by assumption. Hence, what we have shown is that without dispute settlement, and under a wide range of parameter values, symmetric paths are indeed the most severe, because of the feasibility of autarky. 
V OPTIMAL TARIFF AGREEMENTS WITH DISPUTE SETTLEMENT

If there exists a means by which countries can resolve their differences after the game has begun, the optimal tariff agreements of the previous section appear tenuous. Imagine, for example, an agreement has been reached supporting free trade, using the threat of eternal autarky. Suppose also a country deviates from this agreement, taking its one-period optimal tariff welfare over free trade. It is now time for retaliation--autarky forever. Clearly, both countries have an incentive to resolve this problem peaceably and "renegotiate" to a state of at least some trade. However, if countries can return to free trade, then the threat which made free trade possible is no longer there, and free trade is impossible. Hence, in an environment where renegotiation is possible, the only credible threats are those that can be expected to arise from the renegotiation process. Such agreements are said to be "renegotiation-proof."

Unlike subgame perfection, there is no widely accepted condition for renegotiation-proofness. Various authors have advanced notions [e.g. Farrell and Maskin (1987), Pearce (1987), Bernheim and Ray (1987), DeMarzo (1988)], each one differing in the type of group behavior considered to be "reasonable." In this respect, the multiplicity of approaches resembles the multiplicity of solution concepts for cooperative games. ${ }^{11}$ It would appear which concept of renegotiation-proof equilibrium is appropriate depends upon the context in which agreements are renegotiated. Here we are fortunate in that within the context of international trade agreements, such as the GATT, well-defined institutions for assigning of trade sanctions following a breach of the agreement exist: we will refer to these generally as dispute settlement procedures. Rather than advancing a theory of reasonableness of collective action, the approach taken here is to write down a dispute settlement procedure (DSP), which amounts to a rule assigning punishments satisfying certain criteria. We then look for optimal tariff agreements subject to the DSP.

Although it is difficult to generalize about the procedures involved GATT

${ }^{11}$ DeMarzo (1988) has drawn this analogy: "classical cooperative game theory has demonstrated that once we allow group defections, no single, comprehensive, and universally compelling equilibrium concept is likely to emerge. Stable sets, the Core, and the Shapley Value among others have all proved useful in various contexts. Thus, it is not surprising that a non-cooperative game theory expands to encompass varying degrees of communication and coordination between players, different solution concepts will also emerge." Also see Greenberg (1987). 
dispute settlement, 12 the intent of DSPs is to enable countries to consult each other on tariff matters, rather than act unilaterally; to enforce agreements; and to restore of the "balance of concessions," or what is known as reciprocity. ${ }^{13}$ Countries are always encouraged to negotiate prior to any retaliation. At any time, a dispute settlement panel may be set up at the request of either country to determine whether or not an offending policy represents a violation of the GATT. If a country refuses to revoke a policy found to be in violation, then sanctions can be authorized. All panel decisions are subject to the approval of a majority of the Contracting Parties, but rarely do the Contracting Parties act without the approval of the countries involved in the dispute (especially if those countries are large).

In this model, we can abstract from many details of the DSP, because of the assumption of perfect information and the fact that there are only two countries. Tariffs other than the ones specified by the initial path can be observed, are by definition in violation of the agreement and, hence, must constitute an invitation to sanctions. Further, any punishment path recommended by the DSP must be approved by both countries. Clearly, these simplifications diminish the applicability of the model to actual GATT practice; however, the intent here is to build a model in the spirit of the relevant GATT institutions and to examine the implications.

Suppose countries can negotiate agreements, subject to the rule that any violation of the agreement be governed by a dispute settlement procedure. An agreement consists of an initial tariff path and a clause saying, "if any one deviates, go to DSP for further instructions." The DSP specifies a punishment path with the same properties as the original agreement and satisfies:

1) Subgame perfection: no country has an incentive to unilaterally deviate.

2) Reciprocity: each country receives equal welfare from the path. ${ }^{14}$

3) Consistency: the same path is specified whether it is due to a deviation from

\footnotetext{
12Though different procedures govern different sections of the GATT, the most relevant documents are Article XXIII of the GATT and the "Understanding Regarding Notification, Consultation, Dispute Settlement and Surveillance" of 1979.

${ }^{13}$ This characterization of DSP objectives is due to Jackson and Davey (1986). The last is echoed by Long (1985): "...the objective is to restore, with the minimum interference with trade, the balance of concessions and advantage between the parties in the dispute. Conciliation is a key factor in the procedure."

${ }^{14}$ This is slightly weaker than symmetry, which is period-by-period equality of welfare.
} 
the initial path or a previous punishment path. ${ }^{15}$

4) Unanimity: at no time would any country ask for an alternative path satisfying 1-3.

A punishment path satisfying these rules is renegotiation-proof in the sense of Pearce (1987). ${ }^{16}$ According to Pearce, a punishment equilibrium should be Pareto optimal on the set of subgame perfect equilibria that rely on no punishments worse than themselves. To say that is it possible to choose (through renegotiation) a punishment equilibrium $\alpha$, which is supported by another punishment equilibrium $\beta$, where $\beta$ is worse (for both players) than $\alpha$, is to say that $\alpha$ is not an equilibrium, because if anyone were to deviate from $\alpha$, then $\beta$ (which supports $\alpha$ ) would be abandoned in favor of $\alpha$ through renegotiation. Only when $\beta$ is no worse than $\alpha$ can this inconsistency be avoided. The above four conditions on dispute settlement outcomes satisfy Pearce's criterion: subgame perfection (1) is the minimum requirement for selfenforcement; by restricting attention to "reciprocal" punishment paths (2), the unanimity requirement (4) reduces to Pareto efficiency; and the consistency requirement (3) implies that the punishment path is supported by itself, rather than an equilibrium worse than itself.

Optimal tariff agreements are negotiated prior to the start of the game subject to the DSP. Again we look for the best initial path, which is selfenforcing and in which both countries receive equal welfare. Let $\mathrm{v}^{\mathrm{D}}$ be the payoff to a punishment path satisfying $1-4$, let $x^{D}$ maximize $W(x)$, subject to $W(x) \geq(1-\delta) \omega(x)+\delta v^{D}$, and let $W^{D}$ be the one-period payoff associated with $x^{D}$ (the $\delta$ is suppressed for notational simplicity, but it is understood that all of these are functions of the discount factor). Symmetry of the welfare functions imply the existence at least one symmetric Nash equilibrium in the stage game, where $x_{1}=x_{2}=x^{n}$ (this may be autarky). Now consider the following path:

$$
q^{\prime}=\left\{\left(x^{n}, x^{n}\right)_{t=0}^{T-1}, q^{\prime}(T),\left(x^{D}, x^{D}\right)_{t=T+1}^{\infty}\right\}
$$

${ }^{15}$ This might be thought of as a rule of precedent. Jackson and Davey write, "Even though strict "stare decisis" concepts of precedent do not apply.... sometimes the deliberations of international dispute settlement panels or arbiters give every bit the appearance of common law lawyers arguing precedent" [Jackson and Davey (1986, p. 332)].

${ }^{16}$ This extended to the concept of Consistent Bargaining Equilibrium by Abreu, Pearce and Stachetti (1989) and Abreu and Pearce (1990). 
Along this path, both countries choose the Nash equilibrium $x^{n}$ for $T$ periods, followed by a tariff pair $q^{\prime}(T)$, and then choose the lowest available tariffs ( $x^{D}$, $\left.x^{D}\right)$ thereafter. Here $q^{\prime}(T)$ is chooses $x^{n}$ with probability $\lambda$ and $x^{D}$ with $1-\lambda$.

Proposition 3: There exists a punishment path $\mathrm{q}^{\mathrm{D}}$ of the form (10) satisfying conditions 1-4, and $s^{0}=\left\{x^{D}, x^{D}\right\}_{t=0}^{\infty}, s^{i}=q^{D}$, for $i=1,2$ constitute an optimal tariff agreement for any discount factor (subject to the DSP).

Proof in Appendix.

In the absence of a DSP, it was shown that interior stage-game Nash equilibria would generally not play a role in the optimal tariff agreement, because they are neither good enough to be part of the initial path nor bad enough to be part of the punishment path. Instead, autarky would generally be used in the punishment path. In the presence of a DSP, however, interior stagegame Nash equilibria may well be used in the punishment path, and if $\bar{x}<z$, then an interior Nash equilibrium will certainly be used. A path that repeats a symmetric stage-game Nash equilibrium indefinitely satisfies conditions 1-3 of the DSP, but not 4. By restricting the time spent in the Nash equilibrium to $T$ periods, the payoff to the punishment path exceeds that of indefinite repetition of the stage-game Nash equilibrium. Of course, $T$ cannot be too small or $q^{D}$ would not support WD.

The optimal tariff agreement values, $x^{D}, T^{D}$ and $\lambda D$, can be found by maximizing the welfare of the punishment path,

$$
\begin{aligned}
\operatorname{Ew}\left(q^{D}\right)= & \max _{x, T, \lambda}\left\{\left(1-\delta^{T}\right) W\left(x^{n}\right)+(1-\delta) \delta^{T}\left\{\lambda W\left(x^{n}\right)+(1-\lambda) W(x)\right\}+\delta^{T+1} W(x)\right\} \\
= & \max _{x, \rho}\left\{(1-\rho) W\left(x^{n}\right)+\rho W(x)\right\}
\end{aligned}
$$

subject to the conditions of subgame perfection, where again $\rho=\left\{\lambda \delta^{T+1}+(1-\lambda) \delta^{T}\right\}$. The perfection conditions are the analogs of conditions (8a) and (8b) of the previous section. Equation (8b) becomes: $\rho W(x) \geq \omega\left(x^{n}\right)-(1-\rho) W\left(x^{n}\right)$, and noting that $\omega\left(x^{n}\right)=W\left(x^{n}\right)$ by the definition of Nash equilibrium, this constraint is satisfied trivially. Thus the only relevant constraint is the analog of (8a), which reduces to: 


$$
(1-\delta \rho) W(x) \geq(1-\delta) \omega(x)+\delta(1-\rho) W\left(x^{n}\right)
$$

One perhaps instructive way of looking at the solution to this problem is illustrated in figure 2. Let $x^{T}$ maximize $W(x)$ subject to $W(x) \geq(1-\delta) \omega(x)+\delta w\left(q^{T}\right)$, where $q^{T}$ is a path similar to (10) but where the stage-game Nash equilibrium is repeated for $T$ periods $(\lambda=0)$ followed by $x^{T}$ thereafter.

\section{FIGURE 2}

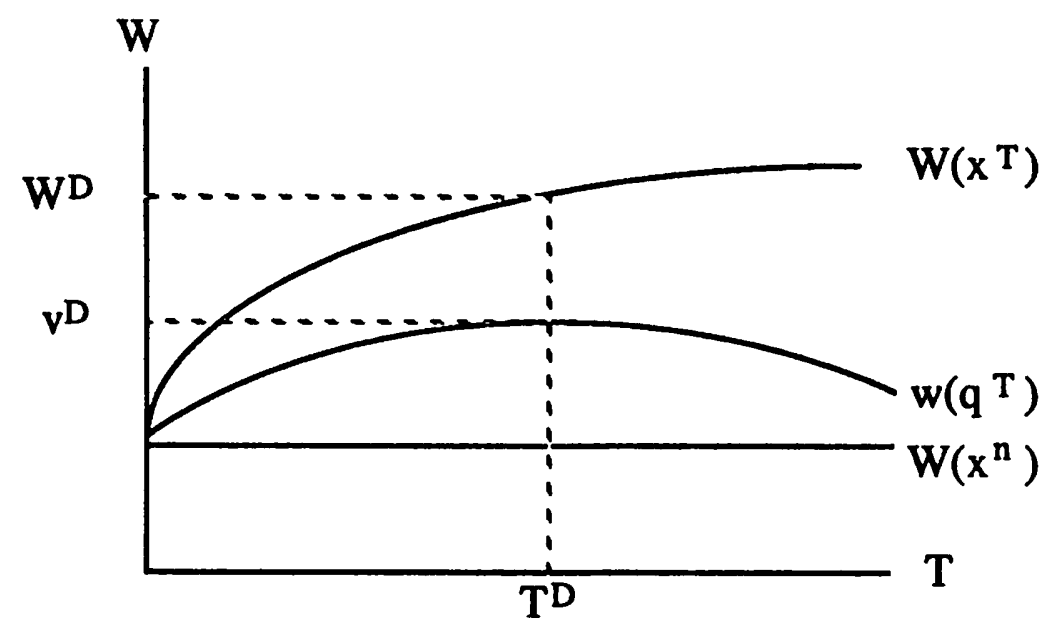

The payoff $W\left(x^{T}\right)$ is the maximum payoff supportable by such a punishment. When $T=0, W\left(x^{T}\right)=W\left(x^{n}\right)$ and $W\left(x^{T}\right)$ will be an increasing function of $T$, as represented in figure 2. The punishment payoff $w\left(q^{T}\right)$ is just a weighted average of $W\left(x^{T}\right)$ and $W\left(x^{n}\right)$ and will be equal to $W\left(x^{n}\right)$ at $T=0$ and at $T=\infty$. The punishment satisfying condition (4) of the DSP is $\max _{T} w\left(q^{T}\right)$, which is reached at $\mathrm{T}^{\mathrm{D}}$.

Several interesting results follow. Perhaps the most important of which is that free trade can never be reached on the initial path of an agreement, when there is a dispute settlement procedure of the form described above. To see this, note that the constraint (11) will always be binding, since if it were not the countries could reduce $T$ (or $\lambda$ ) and increase the payoff $w\left(q^{D}\right)$. However, with a binding constraint, the Kuhn-Tucker theorem implies that if free trade is a solution to the maximization problem, then there is a scalar $k$, such that the derivative of $w\left(q^{D}\right)+k\left[(1-\delta \rho) W(x)-(1-\delta) \omega(x)-\delta(1-\rho) W\left(x^{n}\right)\right]$ is zero, when evaluated at $x=0$. The first order condition reduces to (see appendix for the 
derivation):

$$
\mathrm{W}_{\mathrm{x}}=(1-\delta) \omega_{\mathrm{x}}
$$

where $W_{x}=\partial W / \partial x_{i}+\partial W / \partial x_{j} \leq 0$ and $\omega_{x}=\partial \omega / \partial x$. Since terms of trade effects are exactly offsetting at free trade, $W_{x}(0)=0$, whereas $\omega_{x}(0)<0$, and thus free trade is not part of the optimal tariff agreement, for $\delta<1$.

By way of comparison with the benchmark case, the existence of a dispute settlement procedure of the type described above always leads to lower initial path welfare, more lenient punishments and higher tariffs. However, as countries care more about the future (or lower response time), the welfare levels and tariffs under the two schemes converge to each other and to the free trade levels. All of these results are swept together in proposition 4.

Proposition 4: For $\delta<1$ :

1) $\quad \mathrm{W}(0) \geq \mathrm{W}^{*}(\delta)>\mathrm{WD}^{\mathrm{D}}$ (or, $\mathrm{x}^{\mathrm{D}}>\mathrm{x}^{*}(\delta) \geq 0$ )

2) $\quad \lim _{\delta \rightarrow 1} W^{D}=\lim _{\delta \rightarrow 1} W\left(q^{D}\right)=W(0)$

$$
\text { (or, } \lim _{\delta \rightarrow 1} x^{D}=0 \text { and } \lim _{\delta \rightarrow 1} \rho D=1 \text { ) }
$$

Proof in Appendix.

It should be pointed out that the above results are not necessarily robust to alternative concepts of renegotiation-proof equilibrium. One of the key features of the present DSP is reciprocity, a well-known if not generally accepted rule in the GATT. Some renegotiation-proof equilibrium concepts, most notably Farrell and Maskin (1987), rely on asymmetric punishments to support cooperation, and hence in the presence of reciprocity would allow no cooperation at all. Asymmetric punishments, as used in Cotter and Mitchell (1990), will typically require a deviating country to atone for its indiscretion by eliminating its trade barriers, while allowing the other country impose a high tariff upon it for several periods. This relies on the implicit assumption that renegotiation, if it were to ever occur, would always be resolved in favor of the punishing country. The Pearce notion of renegotiation-proof equilibrium is consistent with the assumption that bargaining power is equal in renegotiation. 17

${ }^{17}$ See Abreu and Pearce (1990) for more detailed discussion. 
No good commercial policy paper would be complete without a moment of reflection on the equivalence (or lack thereof) of tariffs and quotas. Rodriquez (1974) and Tower (1975) used the static model of section 2.1 to demonstrate that tariffs and quotas give rise to substantially different outcomes in the Nash equilibrium. In particular, when quotas instead of tariffs are used as the strategic variable, the unique Nash equilibrium outcome is autarky. The reason for this is similar to the reason Bertrand oligopolists typically price at marginal cost in equilibrium. When a government imposes a binding quota on its imports, it receives the welfare associated with the equivalent tariff (assuming it collects and distributes the quota rents), but the tariff equivalent of a nonbinding quota is zero. This implies each country's best response to a binding quota is always a (possibly only slightly) higher quota, except at autarky. Hence, autarky is the Nash equilibrium.

In international trade agreements this difference between tariffs and quotas remains important. Consider a pair of quotas that gives rise to $W Q=W(x)>$ $W\left(x^{n}\right)$ for each country. The single-period welfare a country receives from optimally deviating from this pair of quotas is $\omega(0)>\omega(x)$ for all $x>0$. Hence, as long as an agreement in quotas supports welfare on the initial path greater then some tariff-Nash equilibrium, the incentive to deviate from that agreement will be greater than the incentive to deviate from the equivalent tariff agreement. This argument is clearly sufficient to establish that, without dispute settlement procedures and whenever autarky is a tariff-Nash equilibrium, optimal tariff agreements are always (weakly) better than optimal quota agreements.

In the presence of a DSP, this result is even cleaner. Notice that the firstorder condition (12) is independent of $W\left(x^{n}\right)$, which implies that the optimal tariff agreement is independent of the (symmetric) Nash equilibrium chosen to comprise the punishment path. Thus, there is no gain in terms of punishment severity per se from using quotas. The minimum payoff to the initial path of any optimal tariff agreement is $\mathrm{W}\left(\mathrm{x}^{\mathrm{n}}\right)$, and if any quota agreement does at least this well on its initial path, then condition (12) is satisfied for $W_{x}\left(x^{D Q}\right)=(1$ $\delta) \omega_{x}(0)$, where $x D$ is the tariff equivalent of the smallest quota level supportable in the optimal quota agreement, subject to the DSP. Since $\omega(x)$ is decreasing and convex, $\omega_{x}(x)$ reaches a global minimum at $x=0$, and $W_{x}$ reaches a global maximum at $x=0$. These functions are illustrated in Figure 3 . 


\section{FIGURE 3}

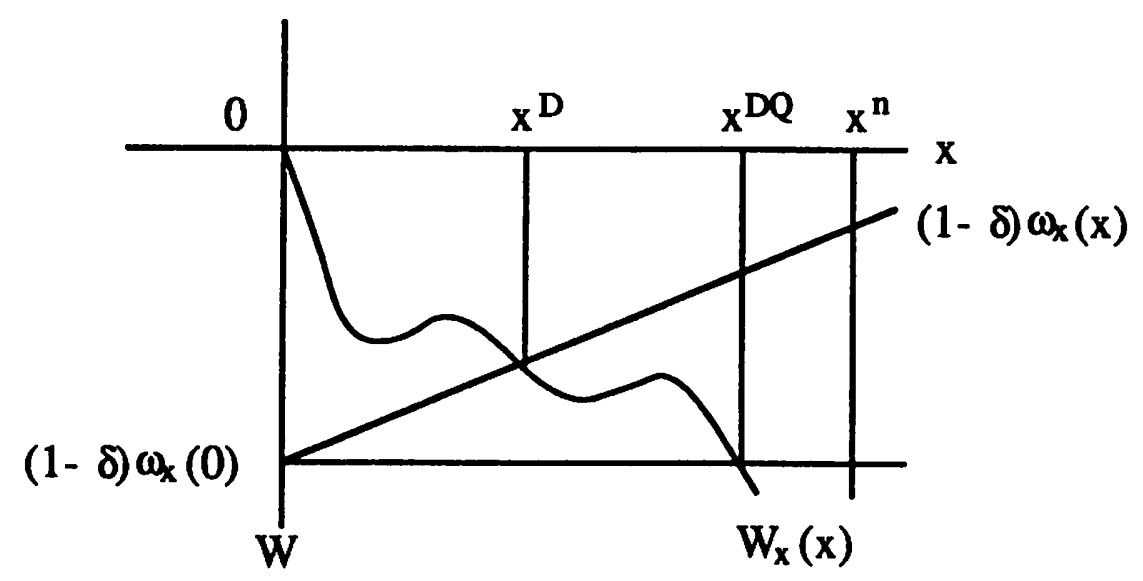

If the function $W_{x}$ crosses the $(1-\delta) \omega_{x}(0)$ line before $x^{n}$, which is the current supposition, then it must cross $(1-\delta) \omega_{x}(x)$ first. The initial path tariff on the optimal tariff agreement, $x^{D}$, is never greater then $x^{D Q}$, and thus optimal tariff agreements weakly dominate optimal quota agreements.

The practical importance of this result is that it supports the long-held GATT convention of converting nontariff barriers into tariff equivalents and then negotiating them away. Rather than relying on the standard argument about tariffs being more "transparent" than quotas, this model suggests that tariffs are preferable simply because quotas carry with them a higher incentive to deviate from any credible agreement.

\section{AN EXAMPLE}

It may be useful to illustrate the results of the previous sections by way of example. This one is taken from Johnson(1953/54). Suppose the two countries have trade utility functions ${ }^{18}$ of the following form:

$$
\mathrm{U}_{1}=\mathrm{aX}-\mathrm{AY}^{\mathrm{a}} \text { and } \mathrm{U}_{2}=\mathrm{aY}-\mathrm{AX}^{\mathrm{a}}
$$

where $a>1, \quad \mathrm{X}$ represents country 1 imports, and $\mathrm{Y}$ is country 1 exports to the country 2 and there is constant import elasticity $\varepsilon=a / a-1$. Utility maximization requires setting the marginal rate of substitution equal to the internal price ratio, which differs from the terms of trade by the tariff wedge:

${ }^{18}$ See Woodland (1982) for a full discussion of trade utility functions. 


$$
\frac{1}{\mathrm{AY}^{\mathrm{a}-1}}=\frac{\left(1+\mathrm{x}_{\mathrm{i}}\right) \mathrm{Y}}{\mathrm{X}}=\left(1+\mathrm{x}_{\mathrm{i}}\right) \pi
$$

This gives the (tariff-ridden) home offer curve, $X=\left(1+x_{1}\right) A^{a}$, and foreign offer curve, $Y=\left(1+x_{2}\right) A X^{a}$. Solving for the equilibrium trade levels we find:

$$
\mathrm{X}=\mathrm{B}\left(1+\mathrm{x}_{1}\right)^{\mathrm{b}}\left(1+\mathrm{x}_{2}\right)^{\mathrm{ba}}, \quad \mathrm{Y}=\mathrm{B}\left(1+\mathrm{x}_{2}\right)^{\mathrm{b}}\left(1+\mathrm{x}_{1}\right)^{\mathrm{ba}}
$$

where $b=1 /\left(1-a^{2}\right)$, and $B=A^{b(1+a)}=A^{1 /(1-a)}$. Substituting (15) into (13) and simplifying gives:

$$
\mathrm{W}_{\mathrm{i}}\left(\mathrm{x}_{\mathrm{i}}, \mathrm{x}_{\mathrm{j}}\right)=\mathrm{B}\left[\mathrm{a}\left(1+\mathrm{x}_{\mathrm{i}}\right)-1\right]\left(1+\mathrm{x}_{\mathrm{i}}\right)^{\mathrm{b}-1}\left(1+\mathrm{x}_{\mathrm{j}}\right)^{\mathrm{ba}}
$$

Note that in deriving (16) we used $b^{2}=b-1$. The first half of $(16),\left[a\left(1+x_{i}\right)-\right.$ $1]\left(1+x_{i}\right)^{b-1}$, represents the proportional benefit of a positive tariff for country $i$. This term is maximized at the optimal tariff, $y_{i}=a-1$, at which point it takes on the value $\mathrm{C} \equiv\left[\mathrm{a}^{\mathrm{b}+1}-\mathrm{a}^{\mathrm{b}-1}\right]$. The second half, $\left(1+\mathrm{x}_{j}\right)^{\mathrm{ba}}$, represents the proportional cost to $i$ associated with tariffs imposed by $j$. This cost is increasing $\left[\left(1+x_{j}\right)^{\text {ba }}\right.$ is decreasing] in $x_{j}$ as ba $<0$. Equation (16) gives,

$$
\begin{aligned}
& W(x)=B[a(1+x)-1](1+x)^{b-1}(1+x)^{b a} \\
& \omega(x)=B C(1+x)^{b a}
\end{aligned}
$$

The fact that the offer curve elasticity is constant implies that $x^{n}=a-1$, and $\mathrm{W}\left(\mathrm{x}^{\mathfrak{n}}\right)=\mathrm{BCa}^{\mathrm{ba}}$ is the stage-game Nash equilibrium payoff.

First consider the benchmark case without dispute settlement. The constant elasticity offer curves imply that the prohibitive tariff is infinite, so let $\bar{x}$ simply be sufficiently large so that $\omega(\bar{x})$ is nearly zero. Using (17) and (18) and the subgame perfection condition $W(x) \geq(1-\delta) \omega(x)$, we get:

$$
[a(1+x)-1](1+x)^{b-1} \geq(1-\delta) C
$$

This simply states that the relative benefit of remaining on the initial path exceeds the normalized relative benefit of the optimal tariff. Maximizing utility (which is equivalent to minimizing $x$ ) subject to $\left(9^{\prime}\right)$, given parameters a and $\delta$, gives the optimal tariff agreement. 
The problem with dispute settlement involves maximizing $(1-\rho) W\left(x^{n}\right)+$ $\rho W(x)$, subject to (11). The first order condition (12) is obtained by differentiating (17) and (18). This can be written as:

$$
[a(1+x)-1](1+x)^{b-1}=(1-\delta) C \frac{a(1+x)-1}{(1+a) x}
$$

or

$$
\mathrm{W}(\mathrm{x})=(1-\delta) \omega(\mathrm{x}) \phi(\mathrm{x})
$$

The term $\phi(x)=\frac{a(1+x)-1}{(1+a) x}$ represents the net effect of the DSP. For $x<y=a-1$, this term strictly greater than 1 , effectively raising the incentive to deviate from any given initial path $x$.

The functions $W(x),(1-\delta) \omega(x)$ and $(1-\delta) \omega(x) \phi(x)$ are drawn together in figure 4 to compare the solutions of the two problems.

\section{FIGURE 4}

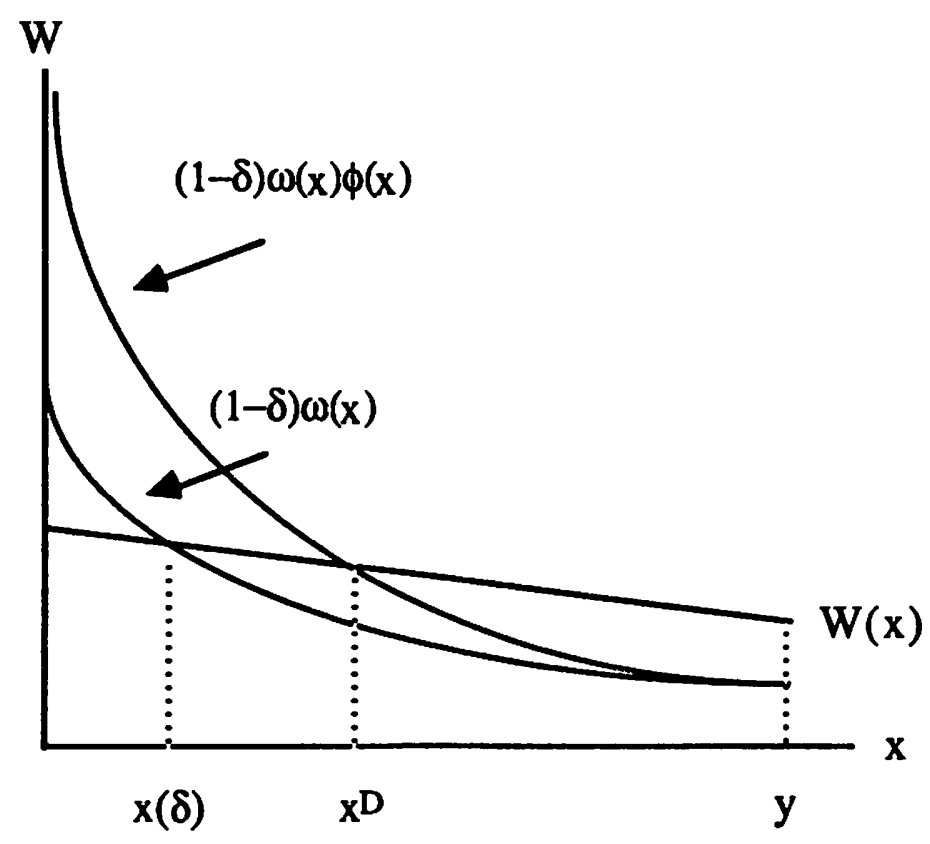

Changing the discount factor $\delta$ results in a shifting of the two constraints by the same proportion. If $\delta$ is lowered to zero (extreme myopia) the two constraints rise to the point where they are tangent to the objective function $W(x)$ at the optimal tariff $(y=1)$. This is just the Johnson tariff war outcome in the stage game. As $\delta$ nears 1 , the no-DSP constraint $(1-\delta) \omega(x)$ falls entirely below $W(x)$, so 
that free trade is supportable. The DSP constraint $(1-\delta) \omega(\mathrm{x}) \phi(\mathrm{x})$ falls mostly below $W(x)$, except at points very near $x=0$, where $\phi(x)$ goes to infinity.

\section{CONCLUSIONS}

This paper has shown that without dispute settlement and under quite general conditions, optimal agreements will resort to autarky, at least temporarily, in the event of a violation of the agreement. Such agreements will support free trade, when discounting is not too severe, and when free trade cannot be supported, no other agreement sustains lower tariffs. When dispute settlement is introduced, optimal trade agreements have a structure very similar to their less constrained counterparts but will never support free trade and always result in higher tariffs. Further, the differences between the two cases become small as countries become patient or lower their response time. With quotas, the incentive to deviate from an agreement is generally higher than with tariffs, and agreements will be more difficult to sustain. For this reason, optimal tariff agreements always give higher (or at least no lower) welfare than optimal quota agreements.

One common criticism of the type of model used here is that, since no country ever deviates in equilibrium, the phenomenon of trade wars cannot be explained. It is not clear, however, that trade wars are as common as is widely believed, especially since the advent of the GATT. The fact that many dispute settlement cases are begun stems from the fact that actual DSPs serve two functions: that of investigating perceived deviations and of authorizing sanctions. Almost no dispute settlement cases ever make it to the sanction stage (Netherlands against US on flour being the one case so far), though a few of cases of retaliation have taken place outside of formal dispute settlement procedures (e.g., the Chicken War). Further, many apparent cases of retaliation may not be deviations at all but attempts to prevent deviations. The recent paper by Bagwell and Staiger (1990) shows that for a given threat of punishment, different states of the world (e.g. import demand surges) result in different incentives to deviate from the initial path, and consequently, an agreement may have to require state-dependent actions (e.g. safeguards), which look like deviations, but are logically quite different. Finally, the most common way to generate trade wars in equilibrium is to assume imperfect monitoring [Copeland (1988), Riezman (1990)]. While imperfect monitoring can be introduced into the 
current framework, with relatively minor revisions to the conclusions, it would be difficult to justify this assumption in the context of GATT-bound tariffs and quotas, where communication and monitoring are quite good.

The question dealt with here is the possibility of communication undermining the threat of punishment that supports the whole system. While the dispute settlement procedure specified in this paper is by no means the only one that could be applied in this context, it does reflect some of the important rules present in the GATT, most notably that of reciprocity. Negotiation (and renegotiation) in games in general is notoriously rule-dependent, and consequently, it is important to examine the effects of rules in contexts were negotiation is important. One interpretation of the GATT is as a supplier of rules designed to direct self-interested countries toward outcomes consistent with pre-agreed goals. The dispute settlement procedures have traditionally been among the most controversial and least understood of these rules. This paper has hopefully provided some understanding.

\section{APPENDIX}

Proposition 1: An agreement specifying $\mathrm{s}^{0}=\left\{\mathrm{x}^{*}(\delta), \mathrm{x}^{*}(\delta)\right\}_{\mathrm{t}=0}^{\infty}$ and SPE paths $\mathrm{s}^{\mathrm{i}}$ such that $w_{i}\left(s^{i}\right)=v(\delta)$, for $i=1,2$ is an optimal tariff agreement for any discount factor.

Proof: By definition $x^{*}(\delta)$ is the best single-period symmetric tariff satisfying the SPE constraint. To establish $s^{0}$ as an optimal initial path, one must show that there exists an optimal initial path that is stationary and symmetric (given $w_{1}\left(s^{0}\right)=w_{2}\left(s^{0}\right)$ ). Given the quasi-concavity of $w_{1}+W_{2}$ and the convexity of $\omega_{i}(x)$, the optimality of stationary and symmetric paths follows from Lemma 1 of Abreu, Pearce and Stachetti (1989), and Lemma 3.3 of Abreu (1983).

Proposition 2: There exists a subgame perfect equilibrium punishment path q⿳亠丷厂巾 the form (7) such that $\operatorname{Ew}(q)=v(\delta)$, for $\delta \geq \delta$.

Proof: Since $\omega(x)$ is decreasing and continuous, $\omega(\bar{x})=\min \{\omega(x)\}$. By (5) and the definition of $v(\delta)$, it must be that $v(\delta) \geq \omega(\bar{x})$. If $\delta \geq \bar{\delta}$, then $\delta W^{*}(\delta) \geq(1-\delta) \omega(\bar{x})+$ $\delta^{2} \mathrm{~W}^{*}(\delta)$, so that there is a SPE path of the form (7), with $T=1$ and $\lambda=0$. This implies $\delta W^{*}(\delta) \geq v(\delta)$. 
Now consider the path $q$ with $T \geq 1$ and $\lambda \in[0,1]$, such that $\operatorname{Ew}(q)=\rho W^{*}(\delta)=$ $v(\delta)$, where $\rho=\left\{\lambda \delta^{\mathrm{T}+1}+(1-\lambda) \delta^{\mathrm{T}}\right\}$. Consider also a path $s^{\prime}$ which is an SPE and $w_{i}\left(s^{\prime}\right)$ $=v(\delta)$ for both $i$. Subgame perfection of $s^{\prime}$ implies:

$$
w_{i}\left(s^{\prime} ; t\right) \geq(1-\delta) \omega_{i}\left(s^{\prime}(t)\right)+\delta v(\delta) \quad \text { for all } t \text { and } i
$$

In the first period of $q$ the countries play $(\bar{x}, \bar{x})$. That $\omega_{i}(\cdot)$ is decreasing implies, $\omega(\bar{x}) \leq \omega_{i}\left(s^{\prime}(t)\right)$ for all $t$ and $i$, which in turn implies,

$$
\begin{aligned}
w_{\mathrm{i}}\left(\mathrm{s}^{\prime}\right) & \geq(1-\delta) \omega(\overline{\mathrm{x}})+\delta \mathrm{v}(\delta) \\
\operatorname{Ew}(\mathrm{q})=(1-\delta) \mathrm{W}(\overline{\mathrm{x}})+\delta \mathrm{Ew}(\mathrm{q} ; 1) & \geq(1-\delta) \omega(\overline{\mathrm{x}})+\delta \mathrm{v}(\delta)
\end{aligned}
$$

and since this is true for $\mathbf{i}$ then by symmetry it also holds for $\mathbf{j}$. This is the condition for SPE in the initial period of $q$. Note further that $E w(q ; t+1) \geq E w(q$; $t$ ), for all $t$. So the condition for SPE is satisfied for $t<T$ and for $T$ whenever $q(T)=\bar{x}$. For $t>T$ and $q(T)=x^{*}(\delta)$ it must be that

$$
\mathrm{W}\left(\mathrm{x}^{*}(\delta)\right) \geq(1-\delta) \omega\left(\mathrm{x}^{*}(\delta)\right)-\delta \mathrm{v}(\delta)
$$

which is true by the definition of $x^{*}(\delta)$.

QED

Proposition 3: There exists a punishment path $\mathrm{q}^{\mathrm{D}}$ of the form (10) satisfying conditions 1-4, and $s^{0}=\left\{x^{D}, x^{D}\right\}_{t=0}^{\infty}, s^{i}=q^{D}$, for $i=1,2$ constitute an optimal tariff agreement for any discount factor (subject to the DSP).

Proof: By condition 4 no path satisfying 1-4 gives the countries less than $v D$. By the definition $x^{D}$, the path $s^{0}$ is supported by $v^{D}$, and, hence, by Proposition $1, s^{0}$ and any SPE $s^{i}$, such that $w_{i}\left(s^{i}\right)=v^{D}$, is an optimal tariff agreement for any discount factor (subject to the DSP).

Evidently, $W^{D} \geq v^{D}$, and since the path $\left(x^{n}, x^{n}\right)_{t=0}^{\infty}$ satisfies $1-3, v^{D} \geq W\left(x^{n}\right)$. Thus, there exists a path $q^{D}$ with $T \geq 1$ and $\lambda \in[0,1]$, such that,

$$
E w\left(q^{D}\right)=\left(1-\delta^{T}\right) W\left(x^{n}\right)+(1-\delta) \delta^{T}\left\{\lambda W\left(x^{n}\right)+(1-\lambda) W^{D}\right\}+\delta^{T+1} W^{D}=v^{D}
$$

Note that along the path $q^{D}, \operatorname{Ew}\left(q^{D} ; t+1\right) \geq \operatorname{Ew}\left(q^{D} ; t\right)$, for all $t$. 
The condition for SPE of $q^{D}$ for $t<T$ and $t=T$ if $q^{D}(T)=x^{n}$ is:

$$
(1-\delta) W\left(x^{n}\right)+\delta E w\left(q^{D} ; t+1\right) \geq(1-\delta) \omega\left(x^{n}\right)+\delta E w\left(q^{D}\right)
$$

which reduces to $\delta \mathrm{Ew}\left(\mathrm{q}^{\mathrm{D}} ; \mathrm{t}+1\right) \geq \delta \mathrm{Ew}\left(\mathrm{q}^{\mathrm{D}}\right)$, as $\mathrm{W}_{\mathrm{i}}\left(\mathrm{x}^{\mathrm{n}}\right)=\omega_{\mathrm{i}}\left(\mathrm{x}^{\mathrm{n}}\right)$, by the definition of Nash equilibrium.

For $t>T-1$ and $t=T$ if $q^{D}(T)=x^{D}$, it must be that:

$$
W\left(x^{D}\right) \geq(1-\delta) \omega\left(x^{D}\right)-\delta E w\left(q^{D}\right)
$$

which is true by the definition of $x^{D}$.

QED

Proposition 4: For $\delta<1$ :

1) $\mathrm{W}(0) \geq \mathrm{W}^{*}(\delta)>\mathrm{WD}^{\mathrm{D}}$ (or, $\mathrm{x}^{\mathrm{D}}>\mathrm{x}^{*}(\delta) \geq 0$ )

2) $\quad \lim _{\delta \rightarrow 1} W^{D}=\lim _{\delta \rightarrow 1} W\left(q^{D}\right)=W(0)$

(or, $\lim _{\delta \rightarrow 1} x^{D}=0$ and $\lim _{\delta \rightarrow 1} \rho D=1$ )

Proof:

1a) Show that $x^{D}>0$ (or $W(0)>W^{D}$ )

By the argument in the text, the constraint must be binding if $x^{D}=0$, so consider the Lagrangian:

$$
L(\rho, x)=w\left(q^{D}\right)+k\left[(1-\delta \rho) W(0)-(1-\delta) \omega(0)-\delta(1-\rho) W\left(x^{n}\right)\right]
$$

First order conditions are:

$$
\begin{aligned}
& \mathrm{L}_{\mathrm{p}}=-\mathrm{W}^{\mathrm{n}}+\mathrm{W}+\mathrm{k}\left(-\delta \mathrm{W}+\delta \mathrm{W}^{\mathrm{n}}\right)=0 \\
& \text { or } \quad \mathrm{k}=1 / \delta \\
& \mathrm{L}_{\mathrm{x}}=\rho \mathrm{W}_{\mathrm{x}}+\mathrm{k}\left[(1-\delta \rho) \mathrm{W}_{\mathrm{x}}-(1-\delta) \omega_{\mathrm{x}}\right]=0 \\
& \text { or } \mathrm{W}_{\mathrm{x}}=(1-\delta) \omega_{\mathrm{x}}
\end{aligned}
$$

Where $W_{x}=\partial W / \partial x_{i}+\partial W / \partial x_{j} \leq 0$. Since the only first-order effect of a small tariff change is the terms-of-trade effect, symmetry of the welfare functions imply that equal tariff changes at free trade must be exactly offsetting. This implies $W_{x}(0)=0$, whereas $\omega_{x}(0)<0$. Thus free trade is not part of the optimal tariff agreement, for $\delta<1$.

1b) Show that $\mathrm{x}^{*}(\delta)<\mathrm{x}^{\mathrm{D}}$ (or $\mathrm{W}^{\mathrm{D}}<\mathrm{W}^{*}(\delta)$ )

Since $v(\delta)$ is by definition at least as low as $v^{D}$, if $x$ satisfies

$$
\mathrm{W}(\mathrm{x}) \geq(1-\delta) \omega(\mathrm{x})-\delta \mathrm{v}^{\mathrm{D}}
$$

then it also satisfies,

$$
W(x) \geq(1-\delta) \omega(x)-\delta v(\delta)
$$

Thus $x^{*}(\delta) \leq x^{D}$. 
If $W^{*}(\delta)=W(0)$, then $W^{*}(\delta)>W^{D}$ by 1a) above. If not, then constraint (9) is binding. This gives the Lagrangian:

$$
\Lambda(x)=W+\mu[W-(1-\delta) \omega(x)-\delta \omega(\bar{x})]
$$

First order conditions:

$$
\begin{aligned}
& \Lambda_{x}=W_{x}+\mu W_{x}-\mu(1-\delta) \omega_{x}=0 \\
& \text { or } \quad W_{x}=(\mu / 1+\mu)(1-\delta) \omega_{x}
\end{aligned}
$$

Since (9) is binding, $\mu$ is positive. If $x^{*}(\delta)=x^{D}$, then by the first order conditions of $1 \mathrm{a})$ and $1 \mathrm{~b})$ : $(1-\delta) \omega_{\mathrm{x}}=(\mu / 1+\mu)(1-\delta) \omega_{\mathrm{x}}$, which implies a contradiction.

2a) Show $\lim _{\delta \rightarrow 1} W^{D}=W_{i}(0)$. Since $\omega$ is continuous and finite for all $x, \lim _{\delta \rightarrow 1}(1$ $\delta) \omega_{x}=0$. And by the Lagrangian first order condition in $1 a$ ), $\lim _{\delta \rightarrow 1} W^{D_{x}}=0$. Hence, if $W_{x}$ is not arbitrarily close to zero for $x>x^{n}$ outside of a neighborhood of zero in $X$ (which can be assumed without any loss of generality), then $\lim _{\delta \rightarrow 1} x^{D}=$ 0 and $\lim _{\delta \rightarrow 1} W^{D}=W_{i}(0)$.

Note that $\lim _{\delta \rightarrow 1} w\left(q^{D}\right)=W\left(x^{n}\right)+\left[W(0)-W\left(x^{n}\right)\right]$ lim $\delta_{\delta \rightarrow 1} \rho D$, so that $w\left(q^{D}\right)$ converges to $W(0)$ if $\rho^{D}$ converges to 1 , which will always happen if $T^{D}$ is finite. Otherwise, $\lim _{\delta \rightarrow 1} w\left(q^{D}\right)=W\left(x^{n}\right)$. But if $T^{D}$ is infinite, there is a finite $T$ such that $(1-\delta \rho) W(0)>(1-\delta) \omega(0)+\delta(1-p) W\left(x^{n}\right)$ for $\delta$ near enough to 1 , which is better for each player than $w\left(q^{D}\right)$. But this violates condition 4 if the dispute settlement rule.

QED

\section{REFERENCES}

Abreu, D. (1983), "Repeated Games with Discounting: A General Theory and an Application to Oligopoly", Ph.D. Dissertation, Princeton University.

(1988), "On the Theory of Infinitely Repeated Games with Discounting", Econometrica, 56(2), 383-396.

, D. Pearce and E. Stachetti (1989), "Renegotiation and Symmetry in Repeated Games", Discussion paper 1440, Harvard University.

and D. Pearce (1990), "A Perspective on Renegotiation in Repeated Games", Hoover Working Paper E-89-31, Stanford University.

Aumann, R. J. (1974), "Subjectivity and Correlation in Randomized Strategies", Journal of Mathematical Economics, 1, 67-96.

Bagwell K. and R. Staiger (1990), "A Theory of Managed Trade", American Economic Review, 80, 799-795. 
Bernheim, B. and D. Ray (1987), "Collective Dynamic Consistency in Repeated Games", mimeo, Stanford University.

Bhagwati, J. and M. Kemp (1969), "Ranking of Tariffs under Monopoly Power in Trade", Quarterly Journal of Economics, 83, 330-335.

Conybeare, J. A. C. (1987), Trade Wars, The Theory and Practice of International Commercial Rivalry, (New York: Columbia University Press).

Copeland, B. R. (1988), "A Theory of Trade Wars", Discussion Paper No: 88-29, University of British Columbia.

Cotter, K. and S. Mitchell (1990), "Renegotiation-Proof Trade Agreements", mimeo.

DeMarzo, P. M. (1988), "Coalitions and Sustainable Social Norms in Repeated Games", IMSSS Technical Report 529, Stanford University.

Dixit, A. (1987), "Strategic Aspects of Trade Policy", in Bewely, T. F. (ed.) Advances in Economic Theory (New York: Cambridge University Press).

Farrell, J. and E. Maskin (1987), "Renegotiation in Repeated Games," Working paper 8759, University of California at Berkeley.

Fudenberg , D. and E. Maskin (1986), "The Folk Theorem in Repeated Games with Discounting or with Imperfect Information," Econometrica, 54(3), 533-554.

Greenberg, J. (1987), The Theory of Social Situations, (Cambridge: Cambridge University Press).

Jackson, J. and W. J. Davey (1986), Legal Problems of International Economic Relations, 2nd ed., (St. Paul, Minn: West).

Jensen , R. and M. Thursby (1980), "Free Trade: Two Non-Cooperative Equilibrium Approaches", Working paper 50, Ohio State University.

Johnson, H. G. (1953-54), "Optimum Tariffs and Retaliation", Review of Economic Studies, 21(2), 142-153.

Jones, R. W. (1969), "Tariffs and Trade in General Equilibrium: Comment," American Economic Review, 59, 418-424.

Long, O. (1985), Law and its Limitations in the GATT Multilateral Trade System, 
(Boston: Nijhoff).

Ludema, R. D. (1990), "International Trade Agreements and GATT Rules: A Game-Theoretic Approach", Ph.D. Dissertation, Columbia University.

Pearce, D. G. (1987), "Renegotiation-Proof Equilibria: Collective Rationality and Intertemporal Cooperation", mimeo, Yale University.

Riezman, R. (1990), "Dynamic Tariffs with Asymmetric Information," Working paper 720, California Institute of Technology.

Rodriguez, C. A. (1974), "The Non-Equivalence of Tariffs and Quotas under Retaliation", Journal of International Economics , 4, 623-640.

Scitovszky, T. de (1942) "A Reconsideration of the Theory of Tariffs", Review of Economic Studies, 9(2), 89-110.

Tower, E. (1975), "The Optimum Quota and Retaliation", Review of Economic Studies , 42, 623-630.

Woodland, A. D. (1982), International Trade and Resource Allocation, (Amsterdam: North-Holland). 